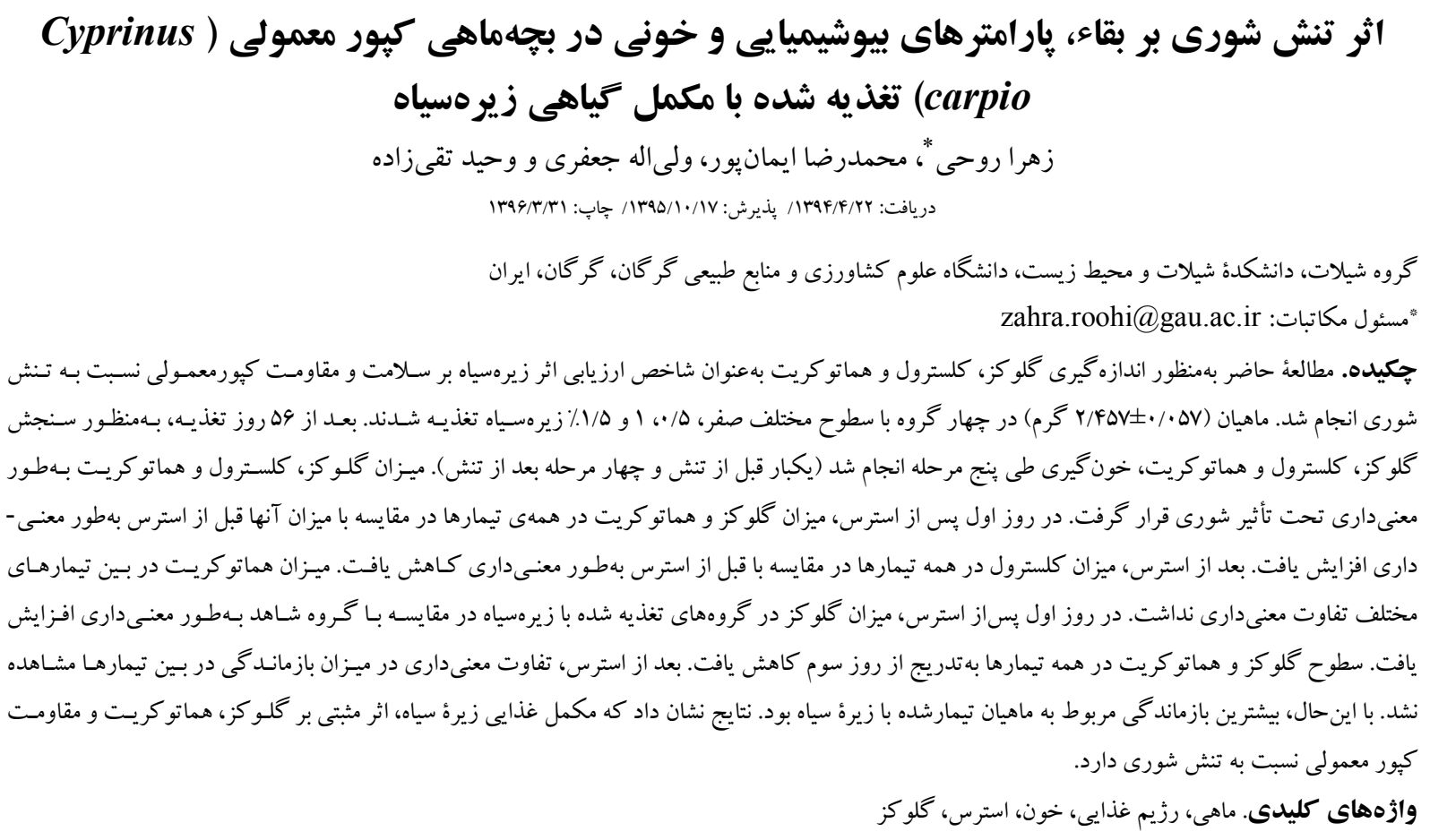

\title{
The effect of salinity stress on survival, biochemical and blood parameters in fingerling Cyprinus carpio fingerling fed with herbal supplement of Carum carvi
} Zahra Roohi*, Mohammad Reza Imanpoor, Valiolah Jafari \& Vahid Taghizadeh Received 13.07.2015/ Accepted 06.01.2017/ Published 21.06.2017

Department of Fisheries and Environment, Gorgan University of Agricultural Sciences and Natural Resources, Gorgan, Iran

*Correspondent author: zahra.roohi@gau.ac.ir

Abstract. This study was conducted in order to measure glucose, cholesterol and hematocrit as indicators to evaluate the effect of caraway seeds meal (CSM) on the health and resistance of common carp to salinity stress. To attain this goal, fish $(2.457 \pm 0.057 \mathrm{~g})$ were divided into four groups fed on diets containing different levels of CSM; 0 (control), $0.5,1$ and $1.5 \%$. After 56 days of feeding, blood samples of the fish were obtained in five stages (once before and four times after stress) to evaluate glucose, cholesterol and hematocrit levels. The experiments indicated that salinity significantly affected glucose, cholesterol and hematocrit. On the first day after stress, the hematocrit and glucose levels were considerably increased in all groups compared with their levels before stress. After stress, cholesterol level significantly decreased in all groups compared to before stress. The level of hematocrit indicated no significant difference among the groups before and after stress. On the first day after stress, the glucose levels significantly increased in treated groups with CSM compared with the control group. The glucose and hematocrit levels were decreased gradually in all groups from the third day on. After stress, no differences were observed for survival rates among the experimental diets. However, the highest survival rate belonged to treated groups with CSM. The overall result indicated that the suplement of CSM has a positive influence on the glucose, hematocrit and resistance of common carp to salinity stress.

Keywords. fish, dietary, blood, stress, glucose

در محدودهُ مورد نياز ماهى حفظ شود تا ميزان رشد و بازماندگى

آن افزايش يابد (Mohammadi-Makvandi et al., 2012).

ماهيان ساز كارىهاى بيوشيميايى و فيزيولوزيكى تكامل يافتهاى

تحت عنوان پاسخ استرس براى مقابله با اين جنين محدوديتها

دارند، كه مانع اثرات زيانآور استرس مىشود و يا آنها را به
مقل مله

عوامل فيزيكوشيميايى آب تأثير بسيار زيادى بر رشد، بقاء و

متابوليسم ماهى دارد كه انحراف از حد مجاز آنها منجر به بروز

مشكلاتى در برورش ماهيان خو اهد شد (Chakraborty, 2007).

بنابراين، بايد سعى شود تا حد امكان عوامل فيزيكوشيميايى آب 
استرسزا مانند دستكارى، كيفيت آب و تغيير در ميزان دما و شورى آب قرار مى گيرند (Wendelaar Bonga, 1997). زيرهسياه گونهاى با براكنش جهانى و سابقه دارويى از دوران باستان (Jayaprakas \& Sambhu, 1996)، در نواحى شمالى نسلى

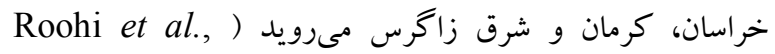

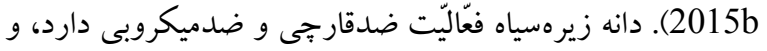

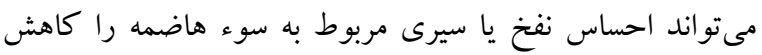
دهد، كه باعث مى شود براى ارتقاء رشد ماهى استفاده شود. اثرات Ahmad \& Abdel Tawwab, ) مثبت اين گياه بر رشد تيلاييا 2011) و كيور معمولى (Roohi et al., 2015b) تأييد شده

در حال حاضر جالش عمده در آبزىيرورى، بهبود جيرههاى غذايى فرموله شده براى بهينهسازى رشد و ارتقاء سلامت ماهيان است (Yousefi et al., 2010). لذا هدف از اين مطالعه بررسى اثر فراك مكمل غذايى زيرهسياه بر باسخهاى فيزيولوزيكك استرس، بهبود روشهاى برورش تجارى و حفظ ذخاير كيور معمولى در محيط -

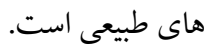

\section{مواد و روشها}

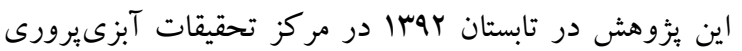
شهيد فضلى بر آبادى دانشگاه علوم كشاورزى و منابع طبيعى گر كان اندان

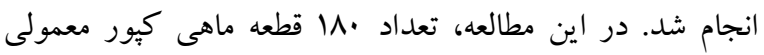

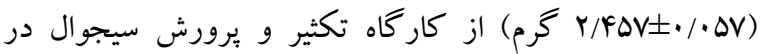

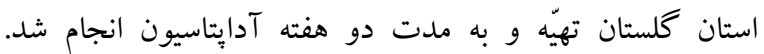

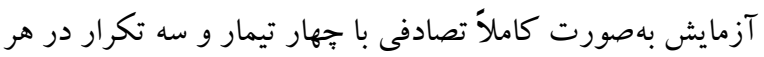

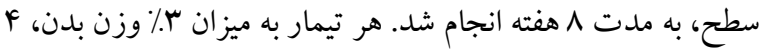
بار در روز تغذيه شدند. هر دو هفته، ماهيان هر تيمار وزن و مقدار

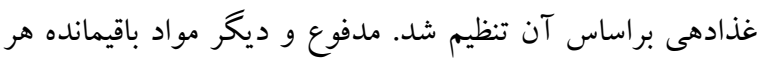

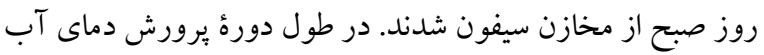

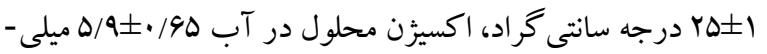

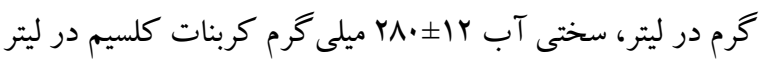

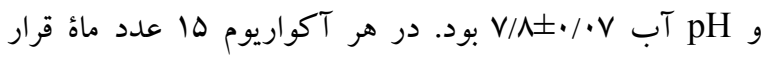

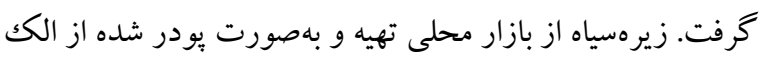

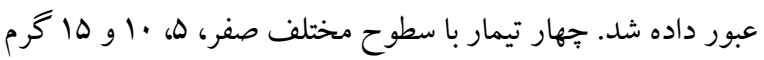

حداقل مىرساند (Koeypudsa \& Jongjareanjai, 2011).

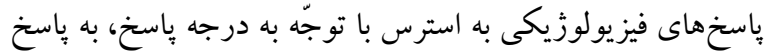

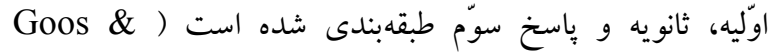
Consten, 2002; Ham et al., 2003 يك تغيير حالت توسط سيستم عصبى مركزى و آزادسازى هورمونهاى استرس، كورتيزول و كاتكو لامينها، توسط سيستم آندوكرين به جريان خون است (Najafpour et al., 2012). ياسخهاى ثانويه بهعنوان اثرات استرس رخخ مىدهد كه منجر به

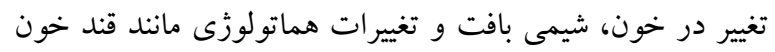
مىشود (Martinez-Porchas et al., 2009). ياسخ سوّم در وضعيت رشد فيزيكى جاندار آشكار مىشود ( Koeypudsa \&

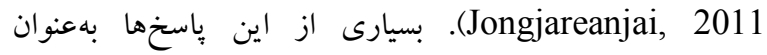

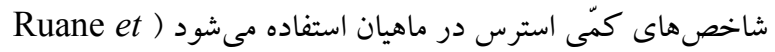
.(al., 1998 يكى از شاخصهاى مهم و قابل اطمينان در بررسى وضعيت

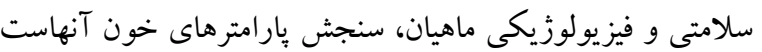
كه از تغذيه، عوامل محيطى و سن اثر مى يذيرد ( Fanouraki et

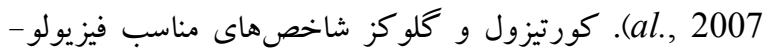
زيكك جهت بررسى رخداد استرس در ماهيان هستند كه به هنگام

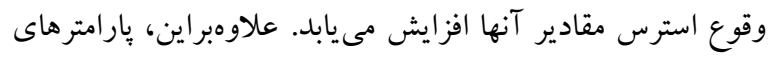

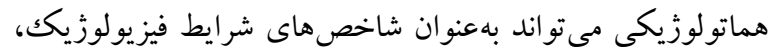
Nضور بيمارى و استرس استفاده شوند ( Najafpour et al.,

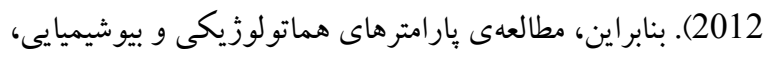

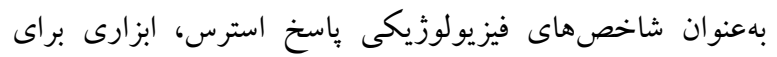
تسهيل مديريت سلامتى ماهيان است (Lermen et al., 2004).

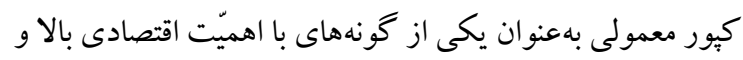
يرطرفدار در اكثر مناطق كشور كشت مىشود ( Al-Dubakel et و جزء مهمترين ماهيان اقتصادى درياى خزر است. در سالهاى اخير به دليل صيد بىرويه مولدين، تغيير در شرايط رودخانها و افزايش آلودگىى، جمعيت مولدين طبيعى كاهش يافته

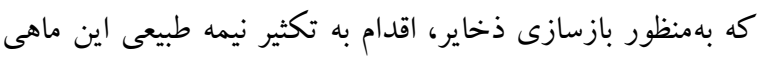

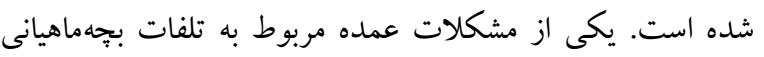
است كه از مراكز تكثير رهاسازى مىشوند (Olla et al., 1988).

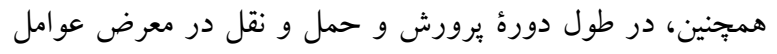


يكك از تيمارهاى آزمايش تفاوت معنىدارى مشاهده نشد. با

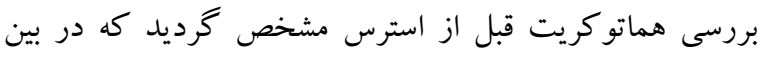

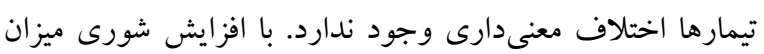

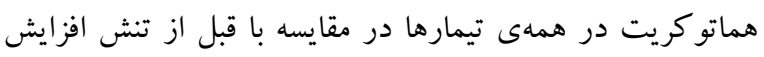

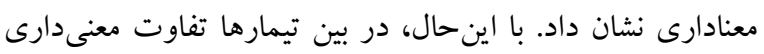

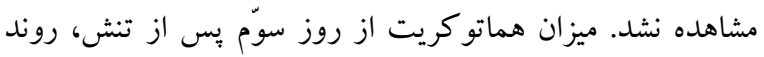

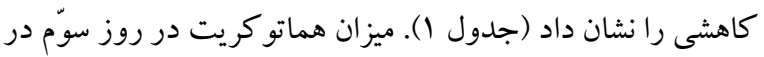

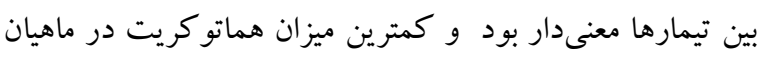
تغذيه شده با زيرهسياه مشاهده شد. قبل از تنش شورى ئن، ميزان كلو كز در تيمارهاى مختلف اختلاف معنادارى داشت و كمترين

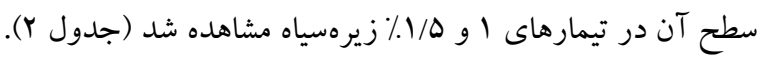
اثر استرس در تغييرات كلوكز معنىدار بود، به طورى كه در روز

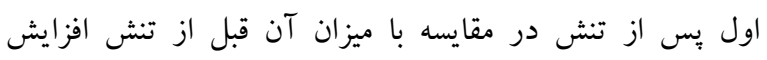

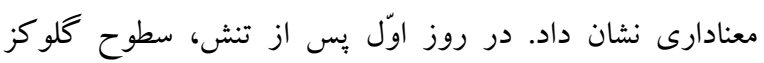

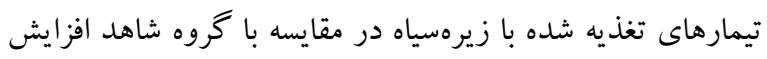
معنى

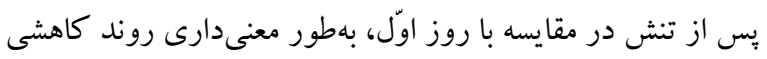

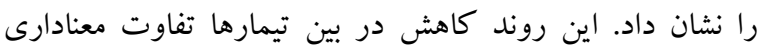

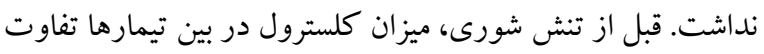
معنى دارى داشت، بهطورى كه بيشترين ميزان كلسترول در كروه

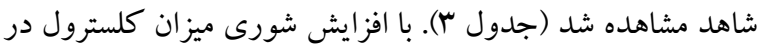

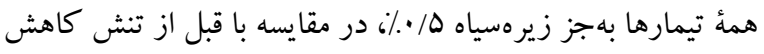
معنادارى نشان داد، با اينحال در بين تيمارها تفاوت معنىدارى رئرياه

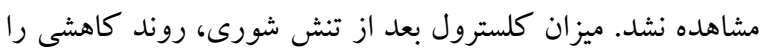
نشان داد. با اينحال، اين روند كاهشى بين تيمارها معنىدار نبود.

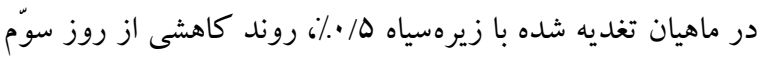
بس از تنش شروع شد.

\section{بحث و نتيجه}

شورى نيز يكى از فاكتورهاى زيستمحيطى است كه بـ برى

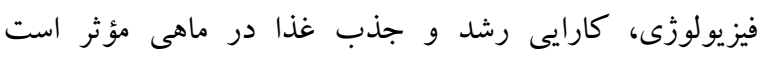
(Mommsen et al., 1998)

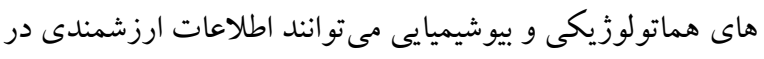

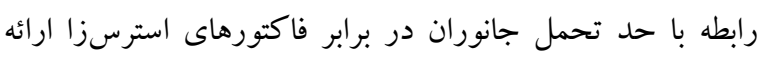
دهند (Barton \& Iwama, 1991) و اندازه كيرى آنها بهعنوان
زيرهسياه در يكى كيلو گرم غذاى تجارى (انرزى |...r) تهيه شد.

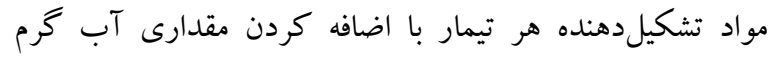

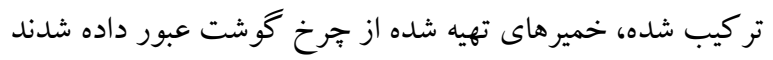

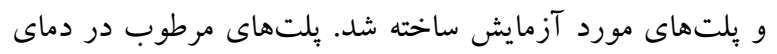
اتاق به مدت r بروز خشك شدند (Mostafa et al., 2009).

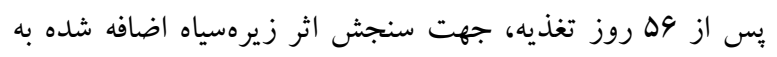

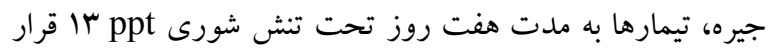

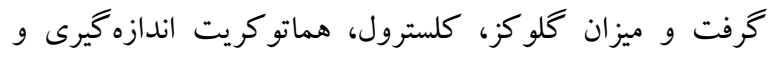
درصد بازماندگى آنها طبق فرمول زير محاسبه شد ( Chimezie .et al., 2008

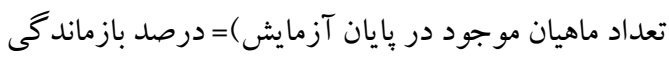

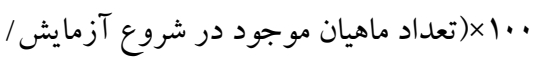

سنجش كلوكز، كلسترول و هماتوكريت

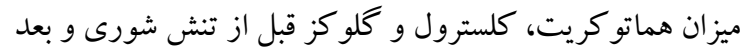
از انتقال ماءٔان به شورى مورد نظر طى جهار مرحله (روزهاى اوّل، تهرئ

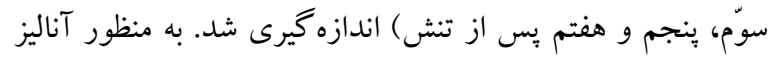
هماتو كريت، نمونههاى خون با قطع ساقه دمى با باستفاده از لوله

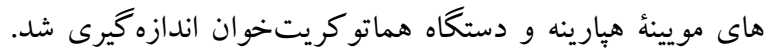

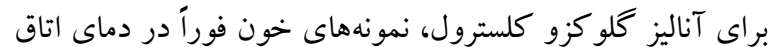

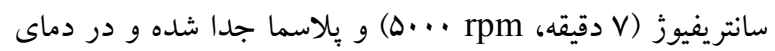

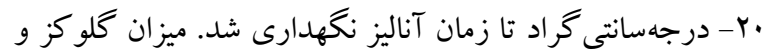

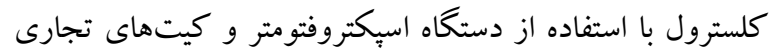

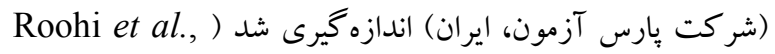
.(2015a تجزيه و تحليل دادهها به روش آناليز واريانس يككطرفه و

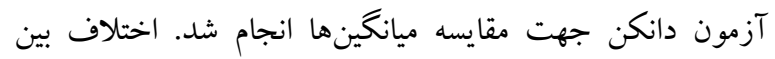

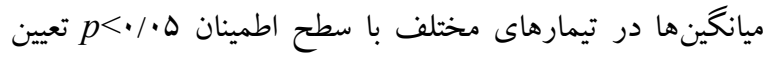

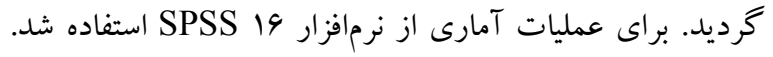

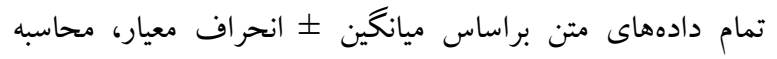

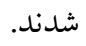
نتايج نتايج مربوط به بازماندگى تيمارهاى مختلف بعد از تنش شورى

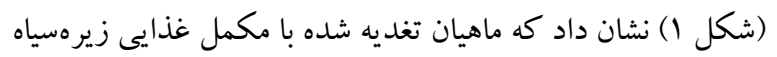

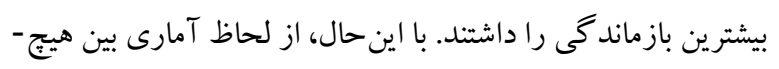




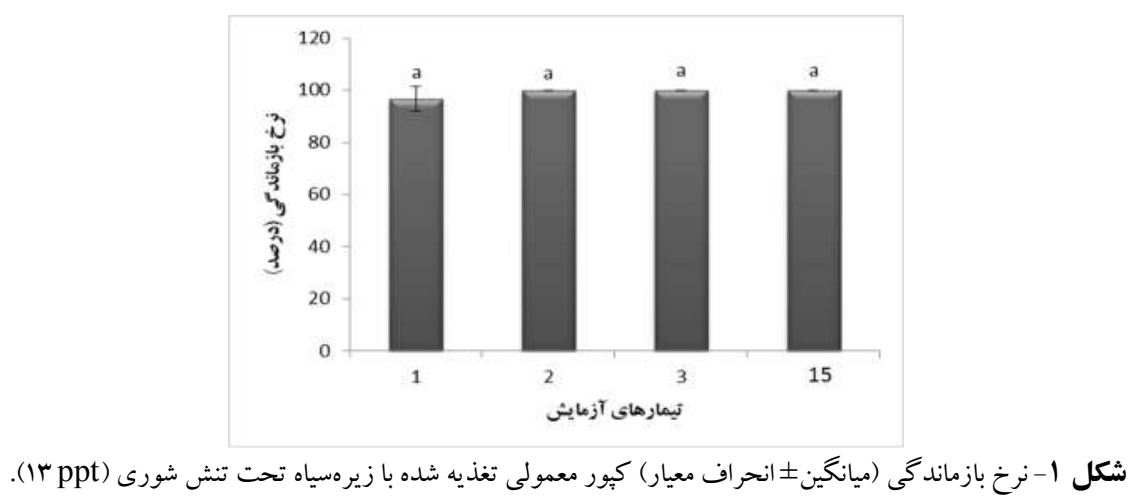

Fig. 1. Survival rate (mean \pm SD) of common carp fed with caraway under salinity stress (13 pt).

جدول ا- غلظت هماتوكريت (ميانخين انحراف معيار) در بجه ماهيان كيور معمولى تغذيه شده بازيرهسياه تحت تنش شورى.

Table 1. Hematocrit levels (mean \pm SD) in common carp fingerlings fed with caraway under salinity stress.

\begin{tabular}{|c|c|c|c|c|}
\hline زيرهُ سياه 1/1٪ & زيره سياه I٪٪ & زيره سياه 0 •٪ & شاهد & هماتوكريت (.) \\
\hline$r q / r \pm r / \varepsilon \cdot \varepsilon^{a C}$ & $r / / \Delta \pm \cdot / 919^{\mathrm{aC}}$ & $r / \wedge \Delta \pm Y / \wedge ৭ q^{\mathrm{aC}}$ & $r|q \pm 1 / f| f^{a D}$ & قبل از تنش \\
\hline $00 / 0 \pm r /|r|^{a A}$ & $4 \cdot \pm r / A Y \Lambda^{a A}$ & $\Delta F / \Delta \pm r / \mid r)^{\mathrm{aA}}$ & $\Delta \mathrm{N} / \Delta \pm \cdot / \mathrm{V} \cdot \mathrm{v}^{\mathrm{aA}}$ & روز اولَ پِساز تنش \\
\hline$\sum Y \pm r / \Lambda T \Lambda^{c B}$ & $F F / \Delta \pm \cdot / v \cdot v^{b c B}$ & $f V / \Delta \pm \cdot / V \cdot V^{a b A B}$ & $\Delta \cdot \pm I / F I f^{\mathrm{aB}}$ & روز سوْم بسىاز تنش \\
\hline$\varepsilon r / r o \pm r / \varepsilon r^{a B}$ & $F F / V \Delta \pm|/ q|^{a B}$ & $r \Delta / \Delta \pm r / \mid r^{\mathrm{aAB}}$ & $r q \pm r / \wedge r^{\mathrm{aC}}$ & روزينجم يساز تنش \\
\hline$\varepsilon r \pm r / A r^{a B}$ & $\kappa \cdot / r \Lambda \pm r / r q^{a B}$ & $F / / \Delta \pm Y / \Lambda r^{a B}$ & $F F / A V \pm Y / 9 \Delta^{a C}$ & روزهفتم بِساز تنش \\
\hline
\end{tabular}

Different lowercase letters in the same and different uppercase letters in the same column indicate significant difference $(p<0.05)$; values are presented as the mean $\pm \mathrm{SD}$.

$$
\text { جدول r- غلظت كلو كز (ميانخين土 انحر اف معيار) در بجه ماهيان كيور معمولى تغذيه شده با زيرهسياه تحت تنش شورى. }
$$

Table 2. Glucose levels (mean $\pm \mathrm{SD}$ ) in common carp fingerlings fed with caraway under salinity stress.

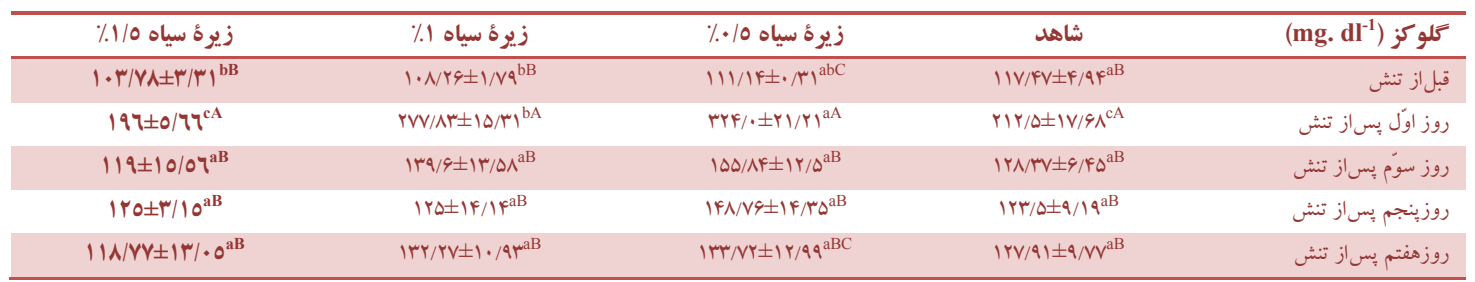

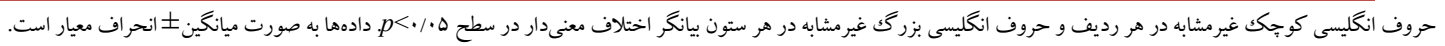
Different lowercase letters in the same and different uppercase letters in the same column indicate significant difference $(p<0.05)$; values are presented as the mean $\pm \mathrm{SD}$.

$$
\text { جدول r- تغييرات كلسترول (ميانخين土 انحر اف معيار) در بجهماهيان كيور معمولى تغذيه شده با زيرهُ سياه تحت تنش شورى. }
$$

Table 3. Cholesterol levels (mean \pm SD) in common carp fingerlings fed with caraway under salinity stress.

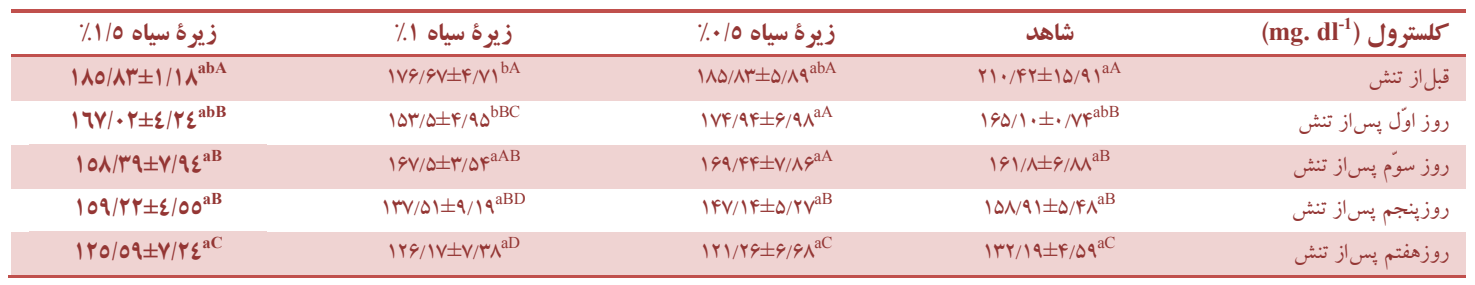

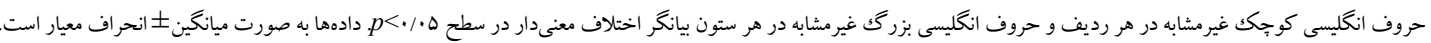
Different lowercase letters in the same and different uppercase letters in the same column indicate significant difference ( $p<0.05)$; values are presented as the mean $\pm \mathrm{SD}$. 
نشان داد كه تصور مىشود اين تغييرات بهدليل ساز گار شدن مـاهى به محيط جديد حاصل شده است. نتايج بهدست آمده بـا مطالعات Cnaani و همكاران (2004) در تيلاييا و Hoseini و Tarkhan

$$
\text { (2013) در ماهى قرمز مطابقت دارد. }
$$

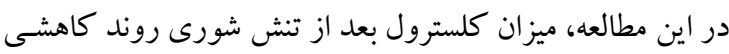
داشت. ماهيان تغذيه شده با زيرهسياه 1٪ نسبت ساير تيمارهـا رونــ دئس

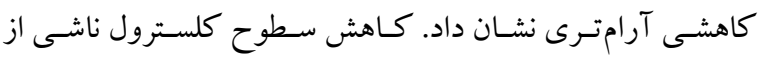

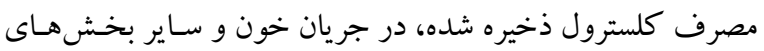

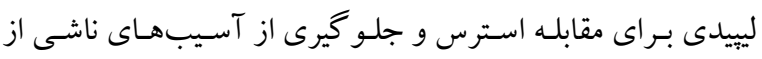

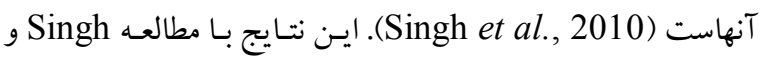
همكاران (2010) بر ماهى Channa punctatus مطابقت دارد. Maita

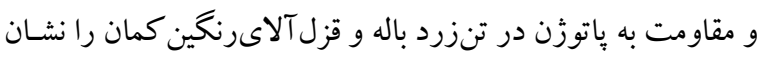

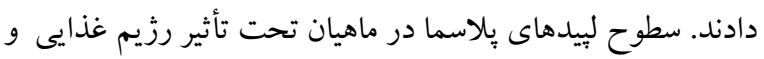
استرس يس از قرار گرفتن در معرض محيطهاى كم اكسيزئن قـرار

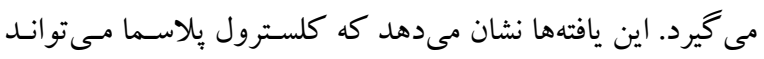

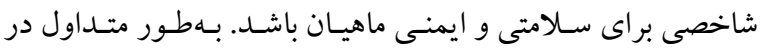
مطالعات تغذيهاى، تـنش شـورى بـراى تعيين كيفيـت بجـهماهيـان

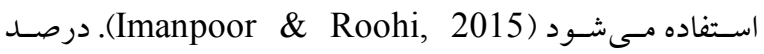

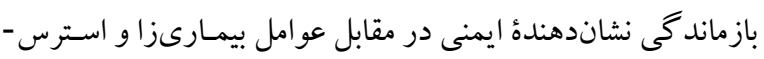
هاى محيطى است (Salze et al., 2008). نتايج اين مطالعه نشـان

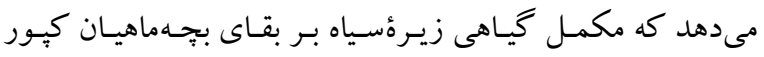

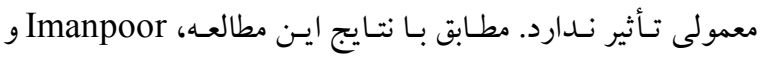
Roohi ميزان بازماندگى بجهماهيان كلمه تحت تنش شورى تأثيرى نداشـته كئه

بلطور كلى، با افزايش شورى، ماهى نياز بيشترى به اكسيزن بيـدا مى كند و تغييراتى در فيزيولوزى ماهى رخخ مىدهـد تـا انـرزى لازم

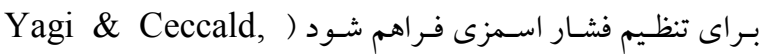

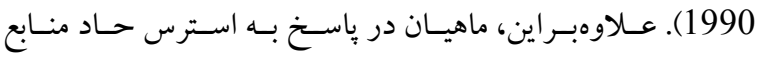

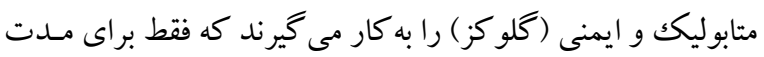

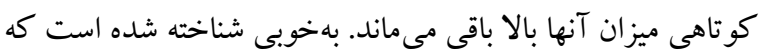

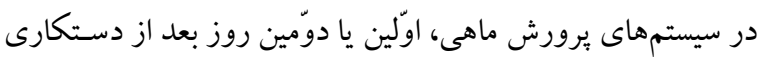

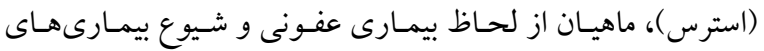

شاخصهـاى فيزيولـوزيكى در ياسـخهـاى ثانويـه استرس بـهـور

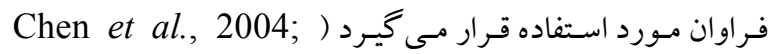
Koeypudsa et al., 2007 . فاكتورهـاى متعـددى مانــد سـن،

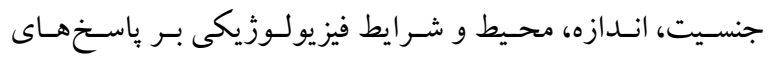

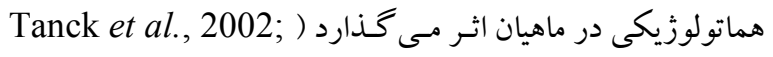
Sowunmi, 2003; Mohammadi Zarejabad et al., 2009). بخشى از حجم كـل خـون كـه توسط كلبـولهـاى قرمـز

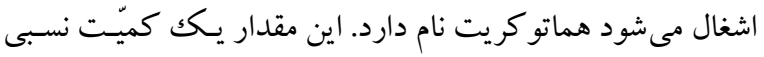
بوده و بر حسب درصد بيان مىشـود. هماتو كريـت خـون بـهعنوان

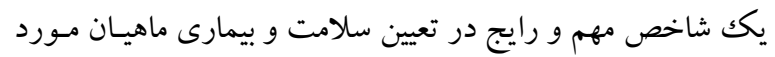

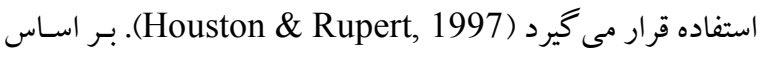
برخى مطالعات، تحت تأثير استرسهاى فيزيكى ميزان هماتوكريت

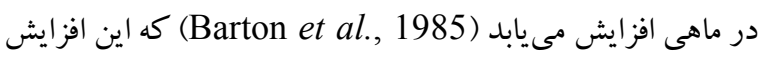

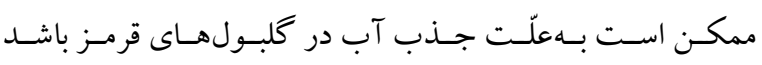
(Milligan \& Wood, 1982) حاصله از آزمايش Malakpour Kolbadinezhad و همكـاران (2012) بر ماهى كلمه نشان مى دهد كه ميزان هماتو كريت در روز

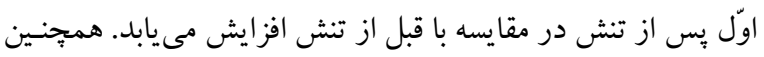

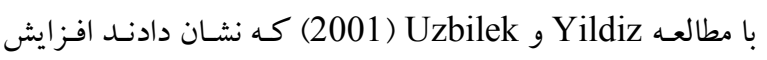
شورى سبب افزايش ميزان هماتوكريـت در مـاهى كيـور علفخـوار

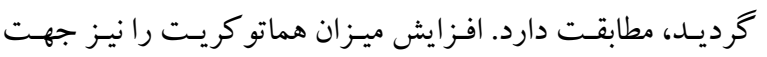

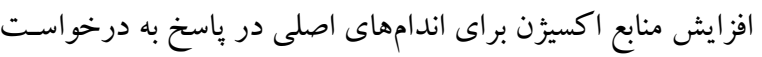

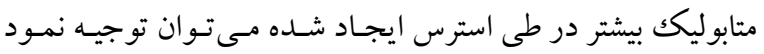
.(Ruane et al., 1998)

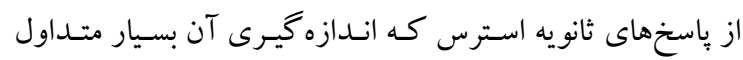

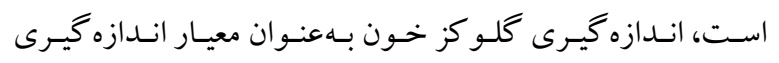
غيرمستقيم هورمون اسـترس اسـت (Makvanid et al., 2012). در اين مطالعه، سطوح كلو كز ماهيان تحت تنش شورى دون در مقايسه

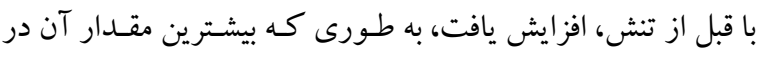

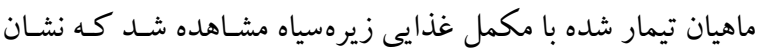

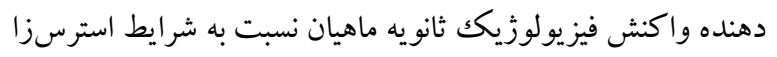

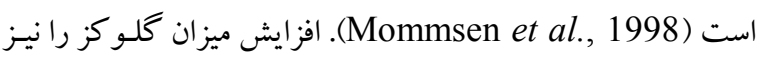
جهت تأمين انرزى براى مقابله با استرس ايجاد شده مىتوان توجيـ

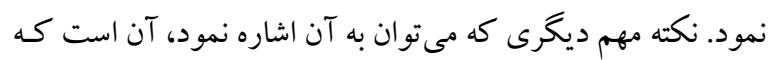

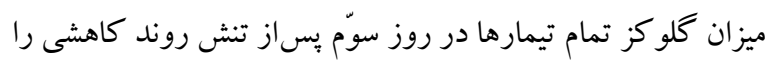




\section{REFERENCES}

Ahmad, M.H. and Abdel Tawwab, H. 2011. The use of caraway seed meal as a feed additive in fish diets: growth performance, feed utilization, and whole-body composition of Nile tilapiya (Oreochromis niloticus) fingerlings. - Aquaculture 314: 110-114.

Al-Dubakel, A.Y., Al-Mhawe, B.H., Majeed, M.F. and Shaeyal, L.W. 2012. Preliminary study on the effect of dietary black seed (Nigella sativa) on growth and blood glucose of common carp (Cyprinus carpio) fingerlings. - J. Agri. Res. 1: 41-51.

Barton, B.A. and Iwama, G.K. 1991. Physiological changes in fish from stress in aquaculture with emphasis on the response and effects of corticosteroids. Ann. Rev. Fish Diseases 1: 2-36.

Barton, B.A., Weiner, G.S. and Schreck, C.B. 1985. Effect of prior acid exposure on physiological responses of juvenile rainbow trout (Salmo gairdnen) to acute handling stress. - Can. J. Fish. Aquat. Sci. 42: 710-717.

Chakraborty, B.K. and Mirza, M.J.A. 2007. Effect of stocking density on survival and growth of endingered bata (Labeo bata) in nursery ponds. - Aquaculture 265: 156-162.

Chen, G.A, Wooster, G.A. and Bowser, P.R. 2004. Comparative blood chemistry and histopathology of tilapia infected with Vibrio vulnificus or Streptococcus iniae or exposed to carbon tetrachloride, gentamicin or copper sulfate. - Aquaculture 239: 421-443.

Chimezie, A., Ibukun, A., Teddy, E. and Francis, O. 2008. HPLC analysis of nicotinamide, pyridoxine, riboflavin and thiamin in some selected food products in Nigeria. - Afr. J. Pharm. 2: 29-36.

Cnaani, A., Tinman, S., Avidar, Y., Ron, M. and Hulata, G. 2004. Comparative study of biochemical parameters in response to stress in Oreochromis aureus, Oreochromis mossambicus and two strains of Oreochromis niloticus. - Aquaculture Res. 35: 1434-1440.

Fanouraki, E., Divanach, F. and Pavlidis, M. 2007. Baseline values for acute and chronic stress indicators in sexually immature red porgy (Pagrus pagrus). Aquaculture 265: 294-304.

Goos, H.J.T. and Consten, D. 2002. Stress adaptation, cortisol and pubertal development in the male common carp (Cyprinus carpio). - Mol. Cell. Endocrinol. 197: 105-116.

Ham, E.H.V., Anholt, R.D.V., Kruitwagen, G., Imsland, A.K., Foss, A., Sveinsbo, B.O., Fitzgerald, R., Parpoura, A.C., Stefansson, S.O. and Bonga, S.E.W. 2003. Environment affects stress in exercised turbot. Comp. Biochem. Phys. A 136: 525-538.

Hoseini, S.M. and Tarkhani, R. 2013. Serum biochemical characteristics of Carassius auratus following short-term formalin or $\mathrm{NaCl}$ treatment. - Int. J. Aqua. Biol. 1: 14-21.
كوناكون و عوامل بيمـارىزا بسـيار حسـاس هسـتند ( Cnaani et

.(al., 2004

$$
\begin{aligned}
& \text { با توجه به نتايج كسب شده از اين تحقيق، مشخص مسىشود كـه } \\
& \text { مكمل غـذايى زيـرهُ سـياه اثر مثبـت و مطلـوبى در بـروز بِاسـخ بـهـ } \\
& \text { استرس در كيور معمولى دارد، بهطورى كـه توانـايى ايـن مـاهى را } \\
& \text { جهت مقابله با استرس شورى افزايش داد. }
\end{aligned}
$$

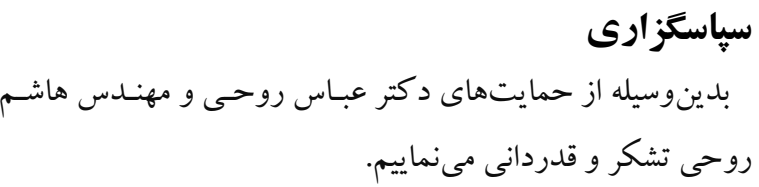


Houston, A.H. and Rupert, R. 1997. Immediate response of hemoglobin system of gold fish (Cyprinus auratus) to tempera change. - Can. J. Zool. 54: 1731-1741.

Imanpoor, M.R. and Roohi, Z. 2015. Effects of sangrovit-supplemented diet on growth performance, blood biochemical parameters, survival and stress resistance to salinity in the Caspian roach (Rutilus rutilus) fry. Aquaculture Res., doi: 10.1111/are.12737.

Jayaprakas, V. and Sambhu, C. 1996. Growth response of white prawn (Penaeus indicus) to dietary L-carnitine. - Asian Fish. Sci. 9: 209-219.

Koeypudsa, W. and Jongjareanjai, M. 2011. Impact of water temperature and sodium chloride $(\mathrm{NaCl})$ on stress indicators of hybrid catfish (Clarias gariepinus $\times$ Clarias Macrocephalus). - Song. J. Sci. Technol. 33: 369-378.

Koeypudsa, W., Kitkamthorn, M., Sadu, K. and Sailasuta, A. 2007. Effect of short-term anoxia (DO 0 ppm, 3 hours) and long-term hypoxia (DO 3-4ppm, 90 days) on haematology of catfish. - J. Health. Res. 21: 13-24.

Lermen, C.L., Lappe, R., Crestani, M., Vieira, V.P., Gioda, C.R., Schetinger, M.R.C., Bald-isserotto, B., Moraes, G. and Morsch, V.M. 2004. Effect of different temperature regimes on metabolic and blood parameters of silver catfish (Rhamdia quelen). Aquaculture 239: 497-507.

Makvanid, H., Khodadadi, M., Keyvanshokoh, S. and Mohammadi-makvandi, Z. 2012. Effect of salinity stress on hormone of cortisol and glucose of Ctenopharyngodon idella. - J. Aquat. Fish. 2: 77-84.

Martinez-Porchas, M., Martinez-Cordova, L. and Ramos-Enriquez, R. 2009. Cortisol and glucose: reliable indicators of fish stress? - Pan-Americ. J. Aquat. Sci. 4: 158-178.

Maita, M., Aoki, H., Yamagata, Y., Satoh, K.I., Okamoto, N. and Watanabe, T. 1998a. Plasma biochemistry and disease resistance in yellowtail fed a non-fish meal diet. - Fish Pathol. 33: 59-63.

Maita, M., Satoh, K.I., Fukuda, N., Okamoto, N. and Ikeda, Y. 1998b. The influence of the dissolved oxygen on levels of plasma components in yellowtail. - Nip. Suis. Guk. 64: 288-289.

Malakpour Kolbadinezhad, S., Hajimoradloo, A., Ghorbani, R., Joshaghani, H. and Wilson, J.M. 2012. Effects of gradual salinity increase on osmoregulation in Caspian roach (Rutilus caspicus). - J. Fish Biol. doi:10.1111/j.1095-8649.2012.03317.x.

Milligan, C.L. and Wood, C.M. 1982. Disturbances in hematology, fluid volume distribution and circulatory function associated with low environmental $\mathrm{pH}$ in the rainbow trout (Salmo gairdneri). - J. Exp. Biol. 99: 397-415.

Mohammadi-Makvandi, Z., Kochin, P., Zanosi, P. 2012. Study of effects of salinity on levels of hemogolobin and hematocrit of sliver carp fingerling (Hypophthalmichthys molitrix). - J. Wetl. Ecobiol. 7: 11-17.

Mohammadi Zarejabad, A., Jalili, M.A., Sudagar, M. and Darvish Bastami, K. 2009. Haematology of great sturgeon (Huso huso) juvenile exposed to brakish water environment. - Comp. Clin. Pathol. doi 10.1007/s00580-009-0888-6.

Mommsen, T.P., Vijayan, M.M. and Moon, T.W. 1998. Cortisol in teleosts: dynamics, mechanisms of action and metabolic regulation. - Rev. Fish Biol. Fish. 9: 211-268.

Mostafa, A.Z.M., Ahmad, M.H., Mousallamy, A. and Samir, A. 2009. Effect of using dried fenugreek seeds as natural feed additive on growth performance, feed utilization, whole-body composition and entropathoge-nic Aeromonas hydrophila-challing of mono sex Nile tilapia fingerlings. - Aust. J. Bas. Appl. Sci. 3: 1234-1245.

Najafpour, B., Imanpoor, M.R. and Shabani, A. 2012. Effects of Rheum palmatum root extract on the blood parameters in responses to two high heat stress and lipid oxidation of Rutilus frisii kutum. - Glob. Veterin. 8: 197-204.

Olla, B.L., Davis, M.W. and Ryer, C.H. 1998. Understanding how the hatchery environment repressses or promotes the development of behavioral survival skills. - Bullet. Mari. Sci. 62: 531-550.

Roohi, Z., Imanpoor, M.R., Jafari, V. and Taghizadeh, V. 2015a. The use of fenugreek seed meal in fish diets: growth performance, haematological and biochemical parameters, survival and stress resistance of common carp (Cyprinus carpio L.). - Aquaculture Res. 46: 1-7.

Roohi, Z., Imanpoor, M.R., Jafari, V. and Taghizadeh, V. 2015b. Effect of different levels of caraway on growth performance and some blood parameters in common carp (Cyprinus carpio). - J. Anim. Environ. 7: 105-112.

Ruane, N.M., Wendelaar Bonga, S.E. and Balm, P.H.M. 1998. Differences between rainbow trout and brown trout in the regulation of the pituitaryinterrenal axis and physiological performance during confinement. Gen. Comp. Endocr. 115: 210-219.

Salze, G., Mclean, E., Schward, M.H. and Craig, S.R. 2008. Dietary mannan oligosaccharide enhances Salinity tolerance and gut development of larval cobia. Aquaculture 274: 148-150.

Singh, A.P., Singh, S., Bhartiya, P. and Yadav, K. 2010. Toxic effect of phorate on the serum biochemical parameters of snake headed fish Channa punctatus. Adv. Biores.1: 177-181.

Sowunmi, A.A. 2003. Hematology of the African catfish (Clarias gariepinus) from Eleiyele Reservoir, Ibadan South-West, Nigeria. - Zool. 2: 85-91.

Tanck, M.W.T., Booms, G.H.R., Eding, E.H., Bonga, S.E. and Komen, J. 2000. Cold shocks: a stressor for common carp. - J. Fish. Biol. 57: 881-894.

Wendelaar Bonga, S.E. 1997. The stress response in fish. - Physiological Reviews 77: 591-625.

Yagi, H. and Ceccald, J.H. 1990. Combind influence of temperature and salinity oxygen consumption of the larval of the pink shrimp (Palaemon sersatus). Aquaculture 86: 77-92. 
Yildiz, H.Y. and Uzbilek, M.K. 2001. The evaluation of secondary stress response of grass carp (Ctenopharyngodon idella) after exposing to the saline water. - Fish. Physiol. Biochem. 25: 287-292.

Yousefi, M., Abtahi, B., Abedian Kenari, A.M. 2010. Effects of captivity and handling stresses on cortisol and glucose levels in giant sturgeon juveniles fed with nucleotide sontained diets. - J. Fish. 63: 147-159.

How to cite this article:

Roohi, Z., Imanpoor, M.R., Jafari, V. and Taghizadeh, V. 2017. The effect of salinity stress on survival, biochemical and blood parameters in fingerling Cyprinus carpio fingerling fed with herbal supplement of Carum carvi. Nova Biol. Rep. 4: 47-54.

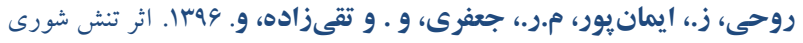

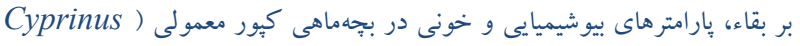
(carpio 